\title{
Functional analysis of pyochelin-/enantiopyochelin-related genes from a pathogenicity island of Pseudomonas aeruginosa strain PA14
}

\author{
Alessandro Maspoli • Nicolas Wenner • \\ Gaëtan L. A. Mislin · Cornelia Reimmann
}

Received: 12 March 2014 / Accepted: 17 March 2014/Published online: 30 March 2014

(C) Springer Science+Business Media New York 2014

\begin{abstract}
Genomic islands are foreign DNA blocks inserted in so-called regions of genomic plasticity (RGP). Depending on their gene content, they are classified as pathogenicity, symbiosis, metabolic, fitness or resistance islands, although a detailed functional analysis is often lacking. Here we focused on a 34-kb pathogenicity island of Pseudomonas aeruginosa PA14 (PA14GI-6), which is inserted at RGP5 and carries genes related to those for pyochelin/ enantiopyochelin biosynthesis. These enantiomeric siderophores of $P$. aeruginosa and certain strains of Pseudomonas protegens are assembled by a thiotemplate mechanism from salicylate and two molecules of cysteine. The biochemical function of several proteins encoded by PA14GI- 6 was investigated by a series of complementation analyses using mutants affected in potential homologs. We found that PA14_54940 codes for a bifunctional salicylate synthase/salicyl-AMP
\end{abstract}

Electronic supplementary material The online version of this article (doi:10.1007/s10534-014-9729-4) contains supplementary material, which is available to authorized users.

A. Maspoli · N. Wenner · C. Reimmann $(\bowtie)$

Département de Microbiologie Fondamentale, Université de Lausanne, Bâtiment Biophore, Quartier UNIL-Sorge,

1015 Lausanne, Switzerland

e-mail: Cornelia.Reimmann@unil.ch

G. L. A. Mislin

Transport Membranaires Bactériens, UMR 7242, Université de Strasbourg-CNRS, Boulevard Sébastien

Brant, BP 10413, Illkirch Cedex, France ligase (for generation and activation of salicylate), that PA14_54930 specifies a dihydroaeruginoic acid (Dha) synthetase (for coupling salicylate with a cysteine-derived thiazoline ring), that PA14_54910 produces a type II thioesterase (for quality control), and that PA14_54880 encodes a serine $O$-acetyltransferase (for increased cysteine availability). The structure of the PA14GI-6-specified metabolite was determined by mass spectrometry, thin-layer chromatography, and HPLC as $(R)$-Dha, an iron chelator with antibacterial, antifungal and antitumor activity. The conservation of this genomic island in many clinical and environmental $P$. aeruginosa isolates of different geographical origin suggests that the ability for Dha production may confer a selective advantage to its host.

Keywords Genomic island · Siderophore · Pseudomonas $\cdot$ Pyochelin · Dihydroaeruginoic acid

\section{Introduction}

The Gram-negative bacterium Pseudomonas aerugin$o s a$ is found ubiquitously in soil and aquatic environments and is virulent towards a large variety of organisms including plants, nematodes, amoeba, insects, and mammals (D'Argenio et al. 2001; Gallagher and Manoil 2001; Plotnikova et al. 2000; Pukatzki et al. 2002). Over the past century, it has 
emerged as an important opportunistic human pathogen causing several nosocomial infections (Van Delden and Iglewski 1998). More notably, P. aeruginosa is recognised as the main cause for chronic lung infection in patients suffering from the genetic disease cystic fibrosis (Lyczak et al. 2002). The ability of $P$. aeruginosa to cause a wide range of acute and chronic infections is based not only on its large arsenal of secreted virulence factors and secondary metabolites but also on its metabolic versatility and high potential for adaptation. Not surprisingly therefore, the $P$. aeruginosa genome is larger than those of most sequenced bacteria and varies between 5.5 and $7 \mathrm{Mbp}$ (Schmidt et al. 1996; Lee et al. 2006). The difference in genome size between strains results from the socalled accessory genome which consists of extrachromosomal elements (e.g. plasmids) and of chromosomal insertions of foreign DNA blocks acquired by horizontal gene transfer. These insertions tend to cluster at certain loci which have been termed "regions of genomic plasticity" (RGP; Mathee et al. 2008). The presence of these chromosomal inserts may confer a selective advantage to the strain and, according to their gene content, these inserts are tentatively assigned as pathogenicity, symbiosis, metabolic, fitness, or resistance islands (Juhas et al. 2008). In many cases however, a functional analysis of the relevant genes has not yet been carried out.

Here we focus on a DNA block inserted at RGP5 in the highly virulent strain PA14 (Mathee et al. 2008). This block, which carries 23 genes (PA14_54850 to
PA14_55090), was originally termed genomic island 6 (PA14GI-6; Song and Zhang 2009) but later described as PA14GI-3 (Song and Zhang 2011); we will use the original designation PA14GI-6 here. Sequence analysis predicted that PA14GI-6 qualified as a pathogenicity island as it carries genes for the biosynthesis of a putative siderophore, for TonB-dependent receptors and ABC transport systems (Song and Zhang 2009). Indeed, some of the PA14GI-6 genes closely ressemble those specifying pyochelin (Pch) and enantiopyochelin (EPch) (Fig. 1), two enantiomeric siderophores produced by $P$. aeruginosa and $P$. protegens, respectively (Youard et al. 2011). Biosynthesis of Pch and EPch proceeds via a thiotemplate mechanism in which salicylate is coupled to two molecules of cysteine which are cyclized and modified during the assembly (Fig. 2; reviewed by Youard et al. 2011). Here we investigate the function of the Pch/EPch-related siderophore biosynthesis genes of PA14GI-6 and we determine the structure of the molecule they specify.

\section{Materials and methods}

Bacterial strains, plasmids and culture conditions

Table 1 lists the strains and plasmids used in this study. Bacteria were routinely cultivated at $37{ }^{\circ} \mathrm{C}$ (Escherichia coli and Pseudomonas aeruginosa) and $30{ }^{\circ} \mathrm{C}$ (Pseudomonas protegens) on nutrient agar and in nutrient yeast broth (Stanisich and Holloway
Fig. 1 Pch and EPch biosynthesis genes of $P$. aeruginosa and $P$. protegens, respectively, and their potential counterparts in genomic island PA14GI6. Genes with significant homology are colored identically

\section{Pyochelin biosynthesis genes in P. aeruginosa PAO1}

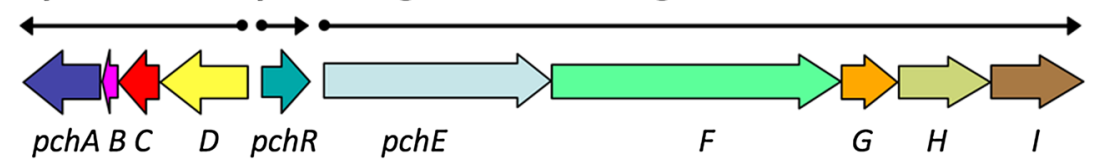

Enantio-pyochelin biosynthesis genes in P. protegens Pf-5 and CHAO

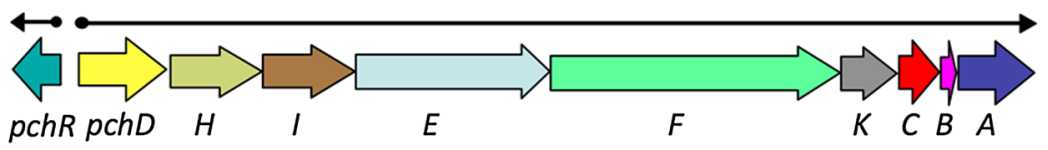

(Enantio-)pyochelin-like biosynthesis genes in genomic island PA14GI-6

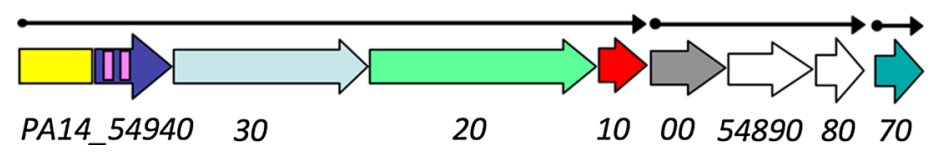




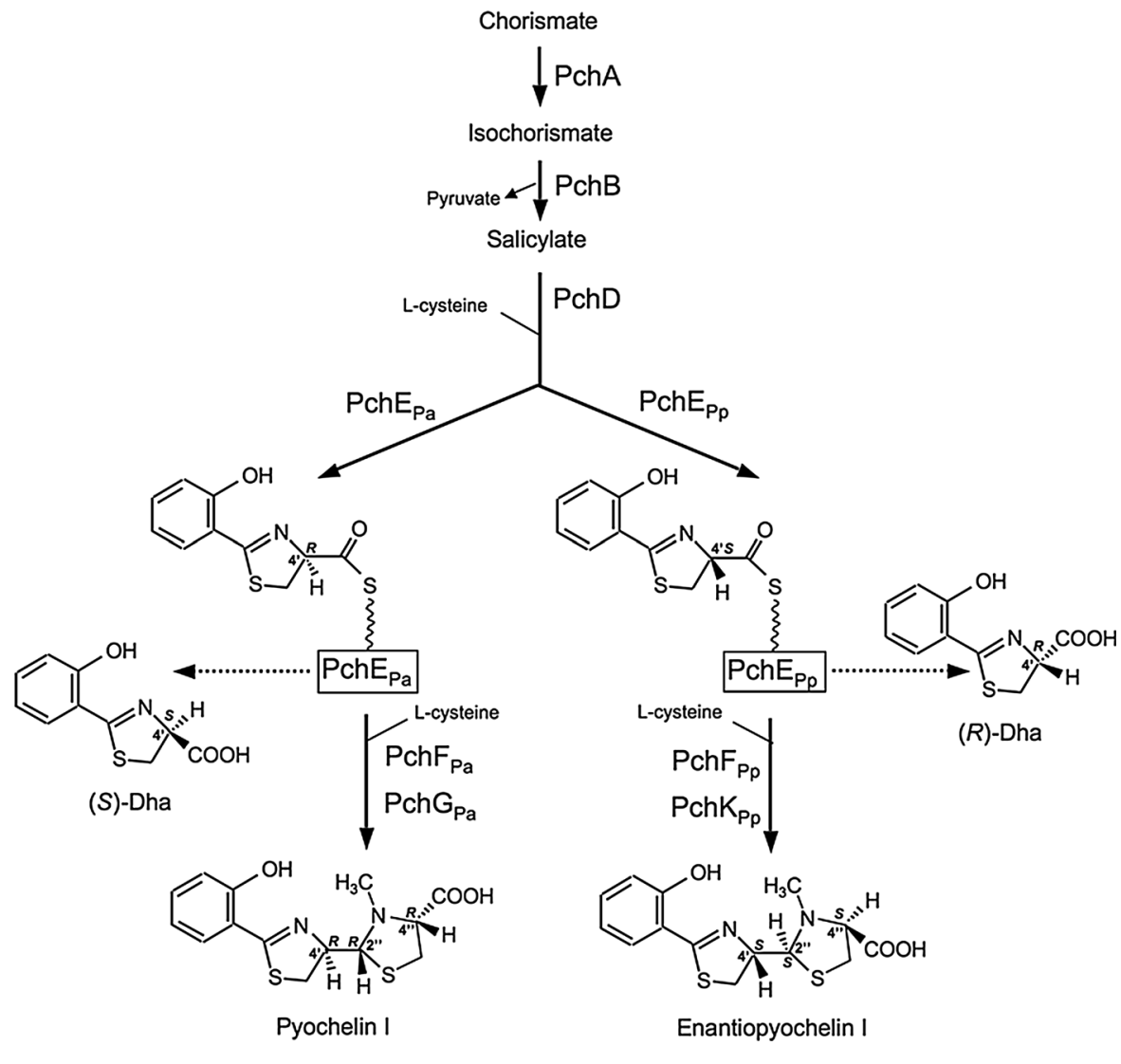

Fig. 2 Biosynthesis of Pch and EPch in P. aeruginosa and $P$. protegens, respectively. Both siderophores are produced by a thiotemplate mechanism from salicylate and two cysteine molecules, which are cyclized during the assembly and undergo a certain number of modifications (reviewed in Youard et al. 2011). For Pch, these are (1) epimerization of the first cysteine by PchE, (2) reduction of the second thiazoline ring by PchG and (3) subsequent $N$-methylation by PchF. EPch assembly is

essentially identical except that it is the second cysteine which is epimerized by a so far uncharacterized mechanism and that reduction appears to be carried out by PchK which has no sequence homology with PchG. Note that premature hydrolysis of the thioester bond of the PchE-attached compound can generate the byproduct Dha (Serino et al. 1997; Patel et al. 2003; Quadri et al. 1999)

1972). To facilite uptake of heterologous DNA during conjugation and transformation, $P$. aeruginosa and $P$. protegens strains were grown at 43 and $35^{\circ} \mathrm{C}$, respectively. For metabolite extraction, bacteria were grown in GGP medium (Carmi et al. 1994) in which iron is present but not immediately accessible, thus inducing the expression of siderophore biosynthesis genes. Production of siderophores was assessed on solid Chrome Azurol S (CAS) agar (Schwyn and Neilands 1987), which turns orange in the presence of iron-chelating molecules. Amino acid complementation experiments with E. coli strain MG1655-C were carried out on solid M9 medium with $0.5 \%$ glycerol as a carbon source (Sambrook and Russell 2001). When needed, antibiotics were added to the

media as follows. For E. coli ampicillin (Ap) was used at $100 \mu \mathrm{g} \mathrm{ml}^{-1}$ while kanamycin $(\mathrm{Km})$ and tetracycline (Tc) were used at $25 \mu \mathrm{g} \mathrm{ml}^{-1}$. For selection of Ap-resistant plasmids in $P$. aeruginosa, carbenicillin $(\mathrm{Cb})$ was used at $250 \mu \mathrm{g} \mathrm{ml}^{-1}$. Tc was used at $125 \mu \mathrm{g} \mathrm{ml}^{-1}$ for both $P$. aeruginosa and $P$. protegens. Counterselection of $E$. coli donor cells during mutant construction occurred with chloramphenicol $(\mathrm{Cm})$ at $10 \mu \mathrm{g} \mathrm{ml}^{-1}$; mutant enrichment was performed with tetracycline at $20 \mu \mathrm{g} \mathrm{ml}^{-1}$ and carbenicillin at $2 \mathrm{mg} \mathrm{ml}^{-1}$ (for $P$. aeruginosa) or cycloserine at $50 \mathrm{mg} \mathrm{ml}^{-1}$ (for $P$. protegens). To activate transcription from tac promoters, isopropyl $\beta$-D-1-thiogalactopyranoside (IPTG) was added at $1 \mathrm{mM}$ final concentration. 
Table 1 Bacterial strains and plasmids

\begin{tabular}{|c|c|c|}
\hline Name & Relevant characteristics & Reference/Source \\
\hline \multicolumn{3}{|l|}{ E. coli strains } \\
\hline $\mathrm{DH} 5 \alpha$ & $\begin{array}{l}\text { recA1 endA1 hsdR17 deoR thi-1 supE44 } \\
\text { gyrA96 relA1 } \triangle(\text { lacZYA-argF) U169 }(\phi \\
\text { 80dlacZDM15) }\end{array}$ & Sambrook and Russell (2001) \\
\hline MG1655 & Wild type & Bachmann (1987) \\
\hline MG1655-C & $\Delta c y s E$ & Sturgill et al. (2004) \\
\hline \multicolumn{3}{|c|}{ P. aeruginosa strains } \\
\hline PALS128 & $p v d B$ & Visca et al. (1992) \\
\hline PAO6334 & $p v d B, p c h G:: \Omega \mathrm{Sp} / \mathrm{Sm}$ & This study \\
\hline PAO6342 & $p v d B, \Delta p c h C$ & Reimmann et al. (2004) \\
\hline PAO6382 & $\Delta p v d F$ & Hoegy et al. (2009) \\
\hline PAO6383 & $\Delta p v d F, \triangle p c h B A$ & Michel et al. (2007) \\
\hline PAO6398 & $\Delta p v d F, p c h D:: \Omega \mathrm{Sp} / \mathrm{Sm}$ & This study \\
\hline PAO6399 & $\Delta p v d F, \Delta p c h E$ & Youard et al. (2007) \\
\hline PAO6402 & $\Delta p v d F, p c h R:: \omega$ & Youard and Reimmann (2010) \\
\hline PA14 & Wild type & Lee et al. (2006) \\
\hline PA14-98 & PA14 $\Delta p v d F$ & This study \\
\hline PA14-99 & $\begin{array}{l}\mathrm{PA} 14 \Delta p v d F \Delta p c h D C B A \Delta p c h R \\
\quad \Delta p c h E F G H I\end{array}$ & This study \\
\hline PA14-106 & $\begin{array}{l}\text { PA14-99 with PA14_54940 to } \\
\text { PA14_54910 under } \mathrm{P}_{t a c} \text { control }\end{array}$ & This study \\
\hline PA14-109 & $\begin{array}{l}\text { PA14-99 with PA14_54940 to } \\
\text { PA14_54910 under } \mathrm{P}_{\text {tac }} \text { control and } \\
\text { PA14_54900 to PA14_54880 under } \\
\text { lacI }{ }_{-} \mathrm{P}_{t a c} \text { control }\end{array}$ & This study \\
\hline A 30 & Environmental isolate $\mathrm{Pa} 4$, Algeria & N. Benzidane \\
\hline A 31 & Environmental isolate Pa5, Algeria & N. Benzidane \\
\hline A34 & Environmental isolate Pa20, Algeria & N. Benzidane \\
\hline A35 & Environmental isolate Pa22, Algeria & N. Benzidane \\
\hline A44 & $\begin{array}{l}\text { Clinical isolate H3471, University } \\
\text { hospital Lausanne, Switzerland } \\
\text { (CHUV) }\end{array}$ & D. Blanc \\
\hline A47 & Clinical isolate $\mathrm{H} 7, \mathrm{CHUV}$ & D. Blanc \\
\hline A90 & $\begin{array}{l}\text { Clinical isolate 7B5, University hospital } \\
\text { Geneva, Switzerland (HUG) }\end{array}$ & C. Van Delden \\
\hline A93 & Clinical isolate $36 \mathrm{D} 5$, HUG & C. Van Delden \\
\hline A97 & Environmental isolate $10289, \mathrm{CHUV}$ & D. Blanc \\
\hline A107 & Environmental isolate 12049 , CHUV & D. Blanc \\
\hline A112 & Environmental isolate $13072, \mathrm{CHUV}$ & D. Blanc \\
\hline A116 & Environmental isolate $7800, \mathrm{CHUV}$ & D. Blanc \\
\hline A117 & Environmental isolate $7852, \mathrm{CHUV}$ & D. Blanc \\
\hline A118 & Environmental isolate $7854, \mathrm{CHUV}$ & D. Blanc \\
\hline A120 & Environmental isolate $7868, \mathrm{CHUV}$ & D. Blanc \\
\hline A122 & Environmental isolate $8093, \mathrm{CHUV}$ & D. Blanc \\
\hline A123 & Environmental isolate $8510, \mathrm{CHUV}$ & D. Blanc \\
\hline A124 & Environmental isolate $8727, \mathrm{CHUV}$ & D. Blanc \\
\hline A134 & Clinical isolate $822, \mathrm{CHUV}$ & D. Blanc \\
\hline
\end{tabular}


Table 1 continued

\begin{tabular}{|c|c|c|}
\hline Name & Relevant characteristics & Reference/Source \\
\hline A135 & Clinical isolate $1161, \mathrm{CHUV}$ & D. Blanc \\
\hline A137 & Clinical isolate $2114, \mathrm{CHUV}$ & D. Blanc \\
\hline \multicolumn{3}{|c|}{$P$. protegens strains } \\
\hline CHA1222 & $\Delta p c h R, p v d:: \operatorname{Tn} 1733, \mathrm{Km}^{\mathrm{r}}$ & Youard and Reimmann (2010) \\
\hline CHA1238 & $\Delta p v d F$ & Reimmann (2012) \\
\hline CHA1262 & $\Delta p v d F, \Delta p c h K$ & This work \\
\hline CHA1264 & $\Delta p v d F, \Delta p c h E$ & This work \\
\hline \multicolumn{3}{|l|}{ Plasmids } \\
\hline pET21a-cysE & $\begin{array}{l}\text { pET21a derivative carrying cysE of } \\
\text { E. coli, } \mathrm{Ap}^{\mathrm{r}}\end{array}$ & Sturgill et al. (2004) \\
\hline pME497 & Mobilizing plasmid, $\mathrm{Ap}^{\mathrm{r}}$ & Voisard et al. (1994) \\
\hline pME3087 & Suicide vector, ColE1 replicon, $\mathrm{Tc}^{\mathrm{r}}$ & Voisard et al. (1988) \\
\hline pME6000 & $\mathrm{pBBR} 1$-based cloning vector, $\mathrm{Tc}^{\mathrm{r}}$ & Maurhofer et al. (1998) \\
\hline pME6032 & lac $I^{Q}-\mathrm{P}_{t a c}$ expression vector, $\mathrm{Tc}^{\mathrm{r}}$ & Heeb et al. (2002) \\
\hline pME6123 & $\begin{array}{l}\text { Identical with pME3087-pchD::SSp/Sm, } \\
\mathrm{Tc}^{\mathrm{r}}, \mathrm{Sp} / \mathrm{Sm}^{\mathrm{r}}\end{array}$ & Serino et al. (1997) \\
\hline pME6176 & $\begin{array}{l}\text { Suicide plasmid to delete } p c h D C B A, \\
p c h R, \text { and } p c h E F G H I \text { in } P \text {. aeruginosa, } \\
\mathrm{Tc}^{\mathrm{r}}\end{array}$ & Reimmann et al. (2001) \\
\hline pME6180 & $\begin{array}{l}\text { Suicide plasmid to generate } p c h G:: \Omega \mathrm{Sp} / \\
\mathrm{Sp} \text { in } P . \text { aeruginosa }, \mathrm{Tc}^{\mathrm{r}}\end{array}$ & Reimmann et al. (2001) \\
\hline pME7152 & $\begin{array}{l}\text { Suicide plasmid to delete } p v d F \text { in } P \text {. } \\
\text { aeruginosa, } \mathrm{Tc}^{\mathrm{r}}\end{array}$ & Michel et al. (2007) \\
\hline pME9244 & $\begin{array}{l}\text { Suicide plasmid to delete } p c h K \text { in } P \text {. } \\
\text { protegens, } \mathrm{Tc}^{\mathrm{r}}\end{array}$ & This study \\
\hline pME9751 & $\begin{array}{l}\text { Suicide plasmid to delete } p c h E \text { in } P \text {. } \\
\text { protegens, } \mathrm{Tc}^{\mathrm{r}}\end{array}$ & This study \\
\hline pME10075 & $\begin{array}{l}\text { pME6032 with PA14_54870 under } \mathrm{P}_{t a c} \\
\text { control, } \mathrm{Tc}^{\mathrm{r}}\end{array}$ & This study \\
\hline pME10201 & $\begin{array}{l}\text { pME6000 with PA14_54930 under } \mathrm{P}_{l a c} \\
\text { control, Tc }{ }^{\mathrm{r}}\end{array}$ & This study \\
\hline pME10202 & $\begin{array}{l}\text { pUCPSK with PA14_54940 under } \mathrm{P}_{l a c} \\
\text { control, } \mathrm{Ap}^{\mathrm{r}}\end{array}$ & This study \\
\hline pME10205 & $\begin{array}{l}\text { pME6000 with PA14_54900 under } \mathrm{P}_{l a c} \\
\text { control, } \mathrm{Tc}^{\mathrm{r}}\end{array}$ & This study \\
\hline pME10208 & $\begin{array}{l}\text { pME3087 carrying a } 1.2 \mathrm{~kb} \text { BamHI- } \\
\text { HindIII fragment containing the } 3^{\prime} \text { part } \\
\text { of PA14_54950 and the } 5^{\prime} \text { part of } \\
\text { PA14_54940 under } \mathrm{P}_{t a c} \text { control, } \mathrm{Tc}^{\mathrm{r}}\end{array}$ & This study \\
\hline pME10209 & $\begin{array}{l}\text { pME6032 with PA14_54880 to } \\
\text { PA14_54900 under } \mathrm{P}_{t a c} \text { control, } \mathrm{Tc}^{\mathrm{r}}\end{array}$ & This study \\
\hline pME10219 & $\begin{array}{l}\text { pME3087 carrying a } 2.8 \mathrm{~kb} \text { EcoRI-XbaI } \\
\text { fragment containing the } 3^{\prime} \text { part of } \\
\text { PA14_54910, } l a c I^{Q}-\mathrm{P}_{t a c} \text {, and the } 5^{\prime} \text { part } \\
\text { of PA14_54900, } \mathrm{Tc}^{\mathrm{r}}\end{array}$ & This study \\
\hline pME10225 & $\begin{array}{l}\text { pUCPSK with PA14_54910 under } \mathrm{P}_{\text {lac }} \\
\text { control, } \mathrm{Ap}^{\mathrm{r}}\end{array}$ & This study \\
\hline pUCPSK & ColE1-pRO1600 shuttle vector, $A p^{r}$ & Watson et al. (1996) \\
\hline
\end{tabular}


DNA manipulations and sequencing

DNA manipulations were carried out according to standard procedures (Sambrook and Russell 2001). Preparations of plasmid DNA were made using Jetstar (Genomed GmbH) and QIAprep Spin Miniprep (Qiagen, Inc.) kits. Chromosomal DNA of P. aeruginosa and $P$. protegens was purified as described by Gamper et al. (1992). DNA fragments were extracted from gels and purified with the Invisorb ${ }^{\circledR}$ fragment cleanUp kit from Invitek. For Southern blotting, chromosomal DNA of $P$. aeruginosa strains was digested overnight with BamHI, separated on a $0.8 \%$ agarose gel, and transferred to a Hybond-N nylon membrane (Amersham Biosciences). DNA probe labeling, hybridization, and detection were done with the DIG DNA labeling and detection kit (Roche) according to the manufacturer's procedures. A DNA probe covering the entire genomic island was prepared from 7 PCR fragments generated from chromosomal DNA of PA14 using the primer pairs GI-1/GI-2bis, GI5/GI-6, GI-7/GI-8, GI-9bis/GI-10bis, GI-13/GI-14, GI-17bis/GI-18bis, and GI-21bis/GI-22bis (Table S1). Transformations of bacterial strains were done by electroporation (Farinha and Kropinski 1990). Constructs based on PCR techniques (for oligonucleotides see Table S1) were sequenced commercially by GATC Biotech.

Construction of mutants and overexpression strains

Gene replacement mutants of $P$. aeruginosa and $P$. protegens (Table 1) were generated as described (Schnider et al. 1995; Ye et al. 1995; Laville et al. 1998). The suicide plasmids carrying the relevant mutations were constructed as follows. First, two PCR fragments were amplified using the template DNA and primer pairs listed in Table S2. Then, the two fragments were combined by overlap extension PCR, and cloned into pME3087, using the restriction sites introduced by the two flanking PCR primers (see Tables S1 and S2). For construction of the suicide plasmid pME10219, which was used to place the PA14_54900 to PA14_54880 operon under $l a c I^{Q}-\mathrm{P}_{\text {tac }}$ control, overlap extension PCR was used to combine three PCR fragments as detailed in Tables S1 and S2.

The resulting suicide plasmids were mobilized from E. coli $\mathrm{DH} 5 \alpha$ to the $P$. aeruginosa and $P$. protegens recipient strains using the helper plasmid pME497 and subsequently integrated into the chromosome with selection for tetracycline resistance. Excision of the vector via a second crossing-over was obtained by enrichment for tetracycline-sensitive cells. Mutants were identified by PCR and sequence analysis. Supplementary Table S2 lists the primer pairs used for generating the suicide plasmids, the $P$. aeruginosa and $P$. protegens recipient strains used for mutant construction, and the designation of the mutants generated in this way.

PCR screening to identify potential GI-6 carriers

Pseudomonas aeruginosa isolates were screened for the presence of GI-6 using the degenerate primers DpchE1 and DpchE5 (Table S1) which were designed based on sequence comparison of pchE from $P$. aeruginosa, P. protegens, Burkholderia cenocepacia, Burkholderia pseudomallei and Burkholderia thailandensis. The primers specify the amino acid sequences HWRSIPY and NGKV/I/LDR which flank the epimerase domain of PchE from $P$. aeruginosa strain PAO1. PCR amplification was performed with GoTaq polymerase (Promega) and whole cell templates in the presence of $5 \%$ DMSO. After initial template denaturation at $95{ }^{\circ} \mathrm{C}$ for $2 \mathrm{~min}, 5$ cycles of amplification were performed with denaturation at $95^{\circ} \mathrm{C}$ for $1 \mathrm{~min}$, annealing at $65^{\circ} \mathrm{C}$ for $1 \mathrm{~min}$, and elongation at $72{ }^{\circ} \mathrm{C}$ for $2 \mathrm{~min}$. Then, another 25 cycles were carried out during which the annealing temperature was lowered to $58{ }^{\circ} \mathrm{C}$. A final extension was done during $3 \mathrm{~min}$. These conditions amplified a fragment of 1,409 bp, characteristic for a pchE gene encoding an epimerase domain (such as $p c h E$ of $P$. aeruginosa PAO1), and a fragment of 524 bp corresponding to a pchE homolog devoid of sequences specifying an epimerase domain (such as PA14_54930 or pchE of $P$. protegens).

Construction of expression plasmids

To analyse the function of PA14GI-6-encoded genes in complementation experiments a series of expression plasmids were constructed. For constitutive expression of PA14_54940 (plasmid pME10202) and PA14_54910 (plasmid pME10225) from $\mathrm{P}_{\text {lac }}$, PCR fragments of $3 \mathrm{~kb}$ (amplified from chromosomal DNA of PA14 using primers 54940fw and 54940bw2) and 
Table 2 Predicted functions of PA14-GI6 specified proteins based on bioinformatics analyses

\begin{tabular}{|c|c|c|c|c|c|}
\hline $\begin{array}{l}\text { Protein of } \\
\text { PA14GI-6 }\end{array}$ & $\begin{array}{l}\text { Protein size } \\
\text { (amino acids) }\end{array}$ & $\begin{array}{l}\text { Homologous } \\
\text { protein }^{\mathrm{a}}\end{array}$ & $\begin{array}{l}\text { Identical amino } \\
\text { acids }(\%)\end{array}$ & $\begin{array}{l}\text { Amino acid } \\
\text { stretch with } \\
\text { homology }\end{array}$ & $\begin{array}{l}\text { Predicted function of the } \\
\text { PA14GI-6 protein }\end{array}$ \\
\hline \multirow[t]{3}{*}{ PA14_54940 } & \multirow[t]{3}{*}{994} & $\operatorname{PchD}(\mathrm{Pa})$ & 52 & $9-522$ & \multirow{3}{*}{$\begin{array}{l}\text { Bifunctional protein with } \\
\text { salicylate synthase and } \\
\text { salicyl-AMP ligase activities }\end{array}$} \\
\hline & & $\mathrm{PchA}(\mathrm{Pa})$ & 30 & $693-975$ & \\
\hline & & Irp9 (Ye) & 41 & $567-981$ & \\
\hline PA14_54930 & 1,113 & $\operatorname{PchE}(\mathrm{Pp})$ & 48 & $1-1,062$ & Dha synthetase \\
\hline \multirow[t]{2}{*}{ PA14_54920 } & \multirow[t]{2}{*}{1,487} & $\operatorname{PchF}(\mathrm{Pp})$ & 45 & 19-933 & \multirow{2}{*}{$\begin{array}{l}\text { Desmethyl-enantiopyochelin } \\
\text { synthetase }\end{array}$} \\
\hline & & $\operatorname{PchF}(\mathrm{Pp})$ & 38 & $955-1,055$ & \\
\hline PA14_54910 & 271 & $\operatorname{PchC}(\mathrm{Pp})$ & 43 & $14-271$ & Type II thioesterase \\
\hline PA14_54900 & 384 & $\operatorname{PchK}(\mathrm{Pp})$ & 31 & $12-333$ & Reductase \\
\hline PA14_54890 & 634 & $\begin{array}{l}\text { No homology to } \\
\text { Pch proteins of } \\
\mathrm{Pa} \text { and } \mathrm{Pp}\end{array}$ & & & $\begin{array}{l}\text { Motifs indicate saccharopine } \\
\text { dehydrogenase, NAD binding } \\
\text { and ATC hydrolase activities }\end{array}$ \\
\hline PA14_54880 & 292 & CysE (Ec) & 50 & $51-287$ & Serine acetyl transferase \\
\hline PA14_54870 & 302 & $\operatorname{PchR}(\mathrm{Pa})$ & 34 & $143-289$ & AraC-type regulator \\
\hline
\end{tabular}

${ }^{a}$ Note that if homology was detected to proteins of $P$. aeruginosa $(\mathrm{Pa})$ and $P$. protegens $(\mathrm{Pp})$, only the protein with stronger homology is listed

$0.9 \mathrm{~kb}$ (primer pair AM-36/AM-37) were cloned via BamHI/SacI and BamHI/XhoI, respectively, into pUCPSK. For constitutive expression of PA14_54930 (plasmid pME10201) and PA14_54900 (plasmid pME10205), PCR fragments of $3.5 \mathrm{~kb}$ (obtained from PA14 with primer pair AM-1/AM-2) and $1.1 \mathrm{~kb}$ (primer pair AM-11/AM-12), were cloned into pME6000 between the restriction sites HindIII/ EcoRI and EcoRI/BamHI, respectively. Inducible expression of the entire PA14_54900-PA14_54890PA14_54880 operon under $\mathrm{P}_{t a c}$ control was obtained with pME10209 as follows. A 3.8-kb PCR fragment was PCR amplified from PA14 using the primer pair AM-11 and AM-13, trimmed with EcoRI and BglII and cloned into pME6032 between the same sites. The PA14_54870 expression plasmid pME10075 was constructed in a similar way. The gene was PCRamplified from PA14 DNA with the primer pair PA14AraC-fw/PA14-AraC-bw, and cloned under $\mathrm{P}_{t a c}$ control into pME6032 using the restriction sites EcoRI and XhoI of the two primers.

Metabolite extraction and analysis

Pseudomonas aeruginosa strains were grown in GGP medium for 2 days to stationary phase $\left(\mathrm{OD}_{600} \sim 7-11\right)$. For HPLC analysis, acidified culture supernatants were extracted with ethyl acetate, dried under reduced pressure, then dissolved in $60 \%$ ( $\mathrm{vol} / \mathrm{vol})$ methanol-
$10 \mathrm{mM} \mathrm{H}_{3} \mathrm{PO}_{4}$, and injected into HPLC systems as reported previously (Reimmann et al. 1998; Youard et al. 2007). Compounds were identified based on their retention times and UV spectra. Preparation of Dha and Pch standards has been described previously (Serino et al. 1997). Electrospray mass spectrometry experiments were done on a microTOF LC from Brucker Daltonics. Analytical Thin-layer chromatography (TLC) was carried out with Merck TLC silica gel $60 \mathrm{~F}_{254}$ on aluminum sheets and $n$-butyl alcohol/water/acetic acid 4:1:1 (v/v/v) as the mobile phase. Compounds were detected by fluorescence at $365 \mathrm{~nm}$ or by spraying with a solution of $\mathrm{FeCl}_{3}$ in $\mathrm{MeOH}$.

\section{Results}

Bioinformatic analysis of PA14_54940 to PA14_54870

As illustrated in Fig. 1, the genes of PA14GI-6, which are potentially involved in the biosynthesis and regulation of a Pch/EPch-related compound, appear to be organized in two operons and a separately transcribed gene. A detailed bioinformatic analysis (Table 2) showed that the N-terminal part of PA14_54940 has strong homology with the salicylAMP ligase PchD of P. aeruginosa while its C-terminal part weakly ressembles isochorismate synthase 
PchA. Interestingly, a stronger homology of the C-terminal part was found with Irp9 of Yersinia enterocolitica, an enzyme which converts chorismate directly to salicylate. We thus predicted that PA14_54940 may have salicylate synthase and salicyl-AMP ligase activities.

The stop codon of PA14_54940 overlaps with the start codon of PA14_54930, which codes for a protein ressembling the peptide synthetases PchE of $P$. protegens $\left(\mathrm{PchE}_{\mathrm{Pp}}\right)$ (Table 2) and P. aeruginosa $\left(\mathrm{PchE}_{\mathrm{Pa}}\right)$ (not shown). These proteins couple salicylate to the first L-cysteine moiety. During Pch biosynthesis (Fig. 2), Lcysteine is converted by a dedicated epimerase domain of $\mathrm{PchE}_{\mathrm{Pa}}$ to its D-enantiomer. Such a domain is absent from PchE $E_{\mathrm{Pp}}$ and PA14_54930, suggesting that PA14_54930 is a Dha synthetase, generating a molecule whose stereochemical configuration at the chiral center $\mathrm{C}^{\prime}$ is identical with that of EPch (Fig. 2).

The third gene of this first operon is PA14_54920; its start codon overlaps with the stop codon of PA14_54930. PA14_54920 displays homology to the Pch and EPch synthetases PchF of $P$. aeruginosa $\left(\mathrm{PchF}_{\mathrm{Pa}}\right)$ and $P$. protegens $\left(\mathrm{PchF}_{\mathrm{Pp}}\right)$, respectively, with a closer relatedness to the latter (Table 2). However, unlike the two PchF proteins, PA14_54920 does not have a dedicated methyltransferase domain required for adding a methyl group to the thiazoline rings of Pch and EPch (Fig. 2). Moreover, the C-terminal part of PA14_54920 has no ressemblance to the thioesterase domains of $\mathrm{PchF}_{\mathrm{Pa}}$ and $\mathrm{PchF}_{\mathrm{Pp}}$. Instead, it presents a typical NAD binding motif, suggesting that product release may be carried out by a thioester reductase mechanism (Du and Lou 2010). PA14_54910, last gene of the PA14_54940 to PA14_54910 operon, encodes a putative type II thioesterase, which is most closely related to $\mathrm{PchC}$ of $P$. protegens. Its $P$. aeruginosa homolog was shown to be required for quality control of Pch biosynthesis by removing wrongly charged substrates from the peptide synthetases PchE and/or PchF (Reimmann et al. 2004).

The second operon potentially implicated in the biosynthesis of a Pch/EPch-related compound is comprised of three genes. The first one, PA14_54900, codes for a protein which is related to PchK of $P$. protegens. Although the function of PchK has not been demonstrated experimentally, the protein is believed to be a functional homolog of PchG, carrying out the reduction of the second thiazoline ring (Fig. 2). In addition to the motifs shared with PchK, bioinformatics identified a motif which is caracteristic of proteins carrying out an epimerase reaction, indicating that PA14_54900 could be a bifunctional protein.

The stop codon of PA14_54900 overlaps with the start codon of PA14_54890. Its deduced amino acid sequence does not reveal homology to proteins implicated in the biosynthesis of Pch and EPch. Based on its NAD binding motif and a certain resemblance with saccharopine dehydrogenases, PA14_54890 may function as an oxidoreductase.

The last gene of the operon, PA14_54880, has no counterpart in the Pch/EPch gene clusters either. However, its deduced amino acid sequence revealed strong homology to CysE of Escherichia coli, an enzyme which converts serine to $O$-acetylserine during cysteine biosynthesis.

The operon PA14_54900 to PA14_54880 is followed by the separately transcribed gene PA14_54870, which codes for an AraC-type regulator ressembling PchR of $P$. aeruginosa $\left(\mathrm{PchR}_{\mathrm{Pa}}\right)$. This protein, and its counterpart in $P$. protegens $\left(\mathrm{PchR}_{\mathrm{Pp}}\right)$ bind their cognate siderophores Pch and EPch, respectively, and upregulate the transcription of the Pch/EPch biosynthesis and transport genes (Lin et al. 2013; Youard et al. 2011).

Taken together, bioinformatics revealed that the siderophore biosynthesis genes of PA14GI-6 appear to be more related to the EPch biosynthetic genes than to those specifying Pch, suggesting that the stereochemistry of the molecule specified by PA14GI-6 could be identical with that of EPch.

Functional analysis of PA14GI-6 genes

In the following, we tested the predicted functions of several PA14GI-6 genes by complementation analyses using $P$. aeruginosa, $P$. protegens and $E$. coli mutants affected in potential homologs. We first evaluated whether PA14_54940 could restore Pch production in $P$. aeruginosa mutants deleted for $p c h B A$ (PAO6383) or carrying an $\Omega$ cassette inserted in $p c h D$ (PAO6398), respectively. Both mutants are pyoverdine (Pvd) negative due to a deletion in $p v d F$, allowing the production of Pch to be evaluated visually by the formation of an orange halo on CAS agar plates. As shown in Fig. 3a, constitutive expression of PA14_54940 from the lac promoter of plasmid pME10202 fully restored Pch production in PAO6383 and also led to a minor production of Pch 
Fig. 3 Functional analysis of PA14_54940 (a), PA14_54930 (b), PA14_54910 (c) and PA14_54880 (d) by complementation analyses. Formation of orange halos around bacterial colonies of Pvd-negative strains grown on CAS agar plates is indicative of Pch $(\mathbf{a}, \mathbf{c})$ or EPch (b) production. Serine acetyl transferase activity was identified by cysteineindependent growth of the indicated E. coli strains on M9 minimal medium containing $1 \mathrm{mM}$ IPTG. Note that growth of the cysE deletion mutant MG1655-C occurred only in close proximity of a filter paper soaked with DL-cysteine
A PAO6382

$(\Delta p v d F)$
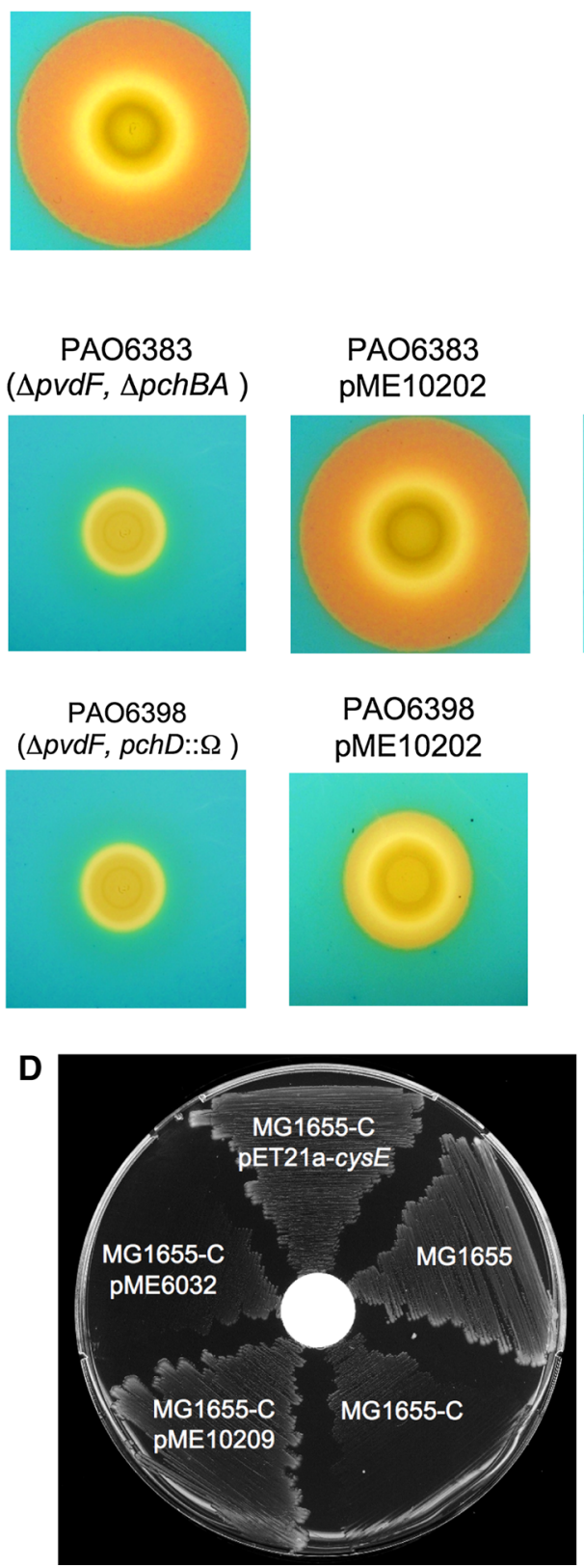

B $\mathrm{CHA} 1238$

$(\Delta p v d F)$

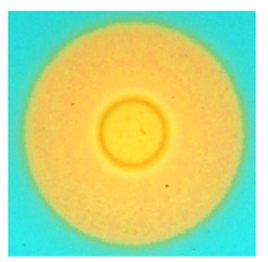

CHA1264 $(\Delta p v d F, \Delta p c h E)$

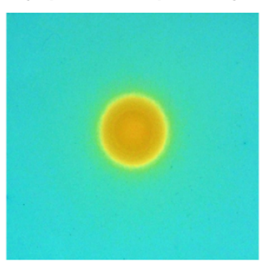

CHA1264

pME10201

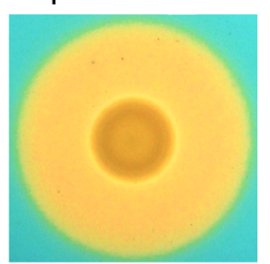

C PALS128

$(p v d B)$

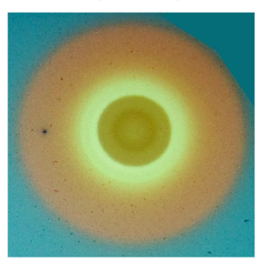

PA6342

$(p v d B, \Delta p c h C)$

pUCPSK

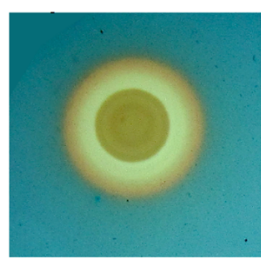

PA6342

pME10225

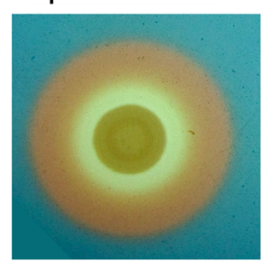

in PAO6398. We thus conclude that PA14_54940 encodes a bifunctional enzyme with salicylate synthase and salicyl-AMP ligase activities.

Next, we addressed the function of PA14_54930, which was expressed under $\mathrm{P}_{\text {lac }}$ control in plasmid pME10201. Introduction of this plasmid restored production of EPch in CHA1264, a Pvd-negative $P$. protegens mutant deleted for
pchE (Fig. 3b). By contrast, PA14_54930 was unable to restore $\mathrm{Pch}$ production in the analogous P. aeruginosa mutant PAO6399 (data not shown). These data show that PA14_54930 specifies indeed a dihydroaeruginoic acid synthetase which is expected to generate the same stereochemical configuration at the chiral center $\mathrm{C}^{\prime}$ than does PchE of P. protegens (Fig. 2). 

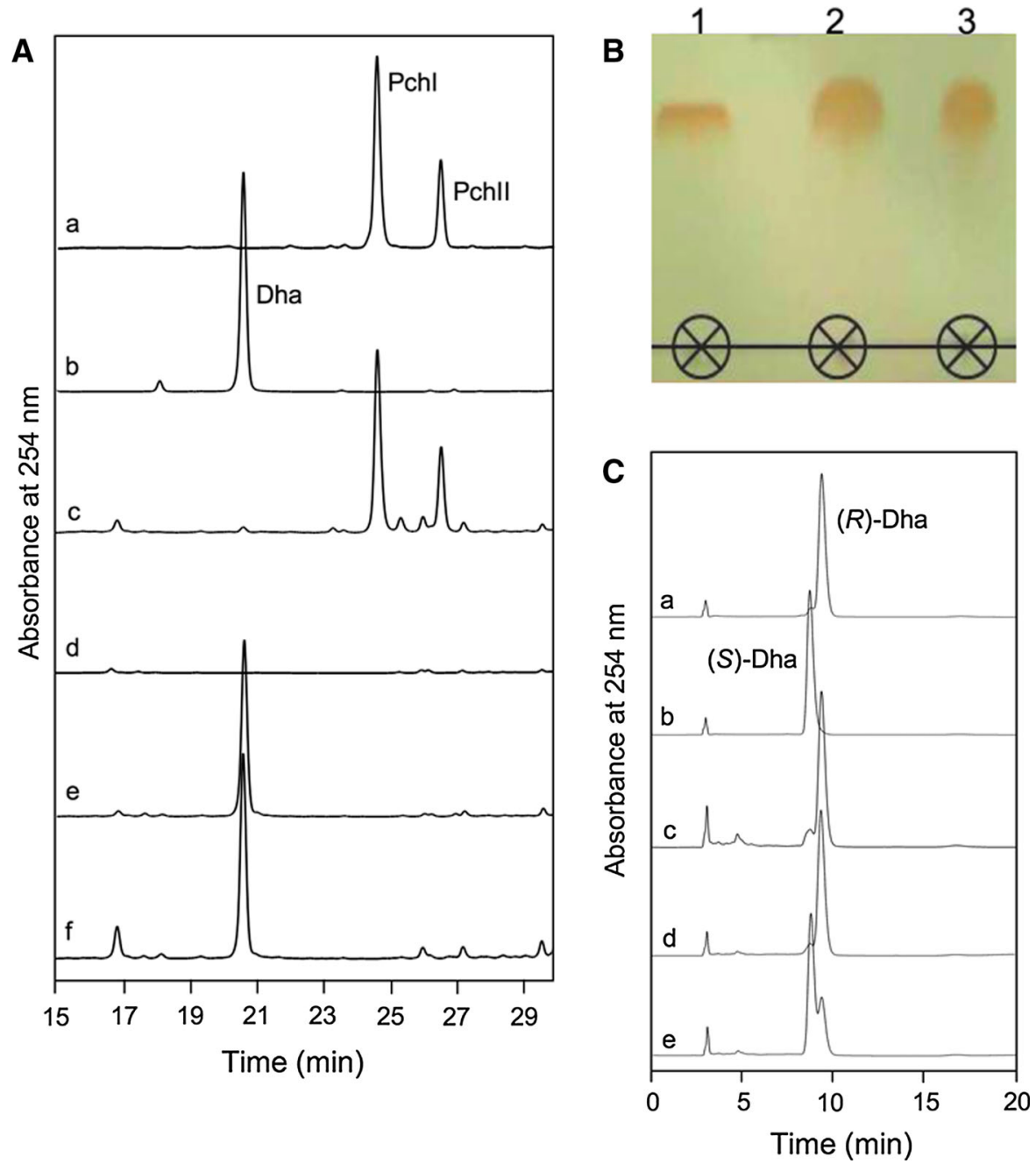

Fig. 4 Identification of the metabolite specified by PA14GI-6 as (R)-Dha. a HPLC analysis of culture supernatant extracts from PA14-98 (trace c), PA14-99 (trace d), PA14-106 (trace e) and PA14-109 (trace f) compared with standards of Pch (trace $a$ ) and Dha (trace $b$ ). Note that due to the spontaneous isomerisation at the chiral center $\mathrm{C} 2$ ", Pch occurs as a mixture of two isomers. EPch was not used as a standard here as the retention times of its two isomers are identical with those of PchI and PchII on the

The function of PA14_54920 was not tested because it seemed unlikely that a protein lacking a dedicated methyltransferase domain would be able to replace PchF in $P$. aeruginosa or $P$. protegens.

Instead, we showed that PA14_54910 is a functional homolog of the type II thioesterase PchC. In agreement with previous observations (Reimmann et al. 2004), we found that pyochelin production was reduced, but not abolished, in the Pvd-negative pchC mutant PAO6342, compared with production in its

reversed phase C-18 column used. b Migration of the PA14GI-6specified metabolite was compared with a Dha standard by thin layer chromatography. Lane 1 metabolite; lane 2 co-spot; lane 3 Dha standard. c Chiral HPLC of culture supernatant extract from PA14-109 (trace c) compared with standards of $(R)$-Dha (trace a) and $(S)$-Dha (trace $b)$. Trace $d$, metabolite mixed with $(R)$-Dha; trace $e$, metabolite mixed with $(S)$-Dha

PchC-positive parent strain PALS128 (Fig. 3c). Constitutive expression of PA14_54910 on plasmid pME10225 partially restored Pch production, confirming the predicted role of this PchC homolog in quality control of siderophore assembly.

We then evaluated wether PA14_54900 would be able to complement the Pvd-negative $p c h K$ mutant CHA1262. However, no siderophore production by CHA1262 was observed when PA14_54900 was expressed from the lac promoter of pME10205 (data not shown). 
Fig. 5 Occurrence of GI-6 in environmental and clinical $P$. aeruginosa isolates. a Genes of GI-6 in the chromosome of strain PA14 and size of DNA fragments generated by in silico restriction with BamHI (in bp). b BamHI fragments of chromosomal DNA of PA14, PAO1 and of 21 GI-6 carriers were separated by agarose gel electrophoresis, transferred to a nylon membrane and hybridized against a PA14GI-6-specific digoxygenin-labeled DNA probe
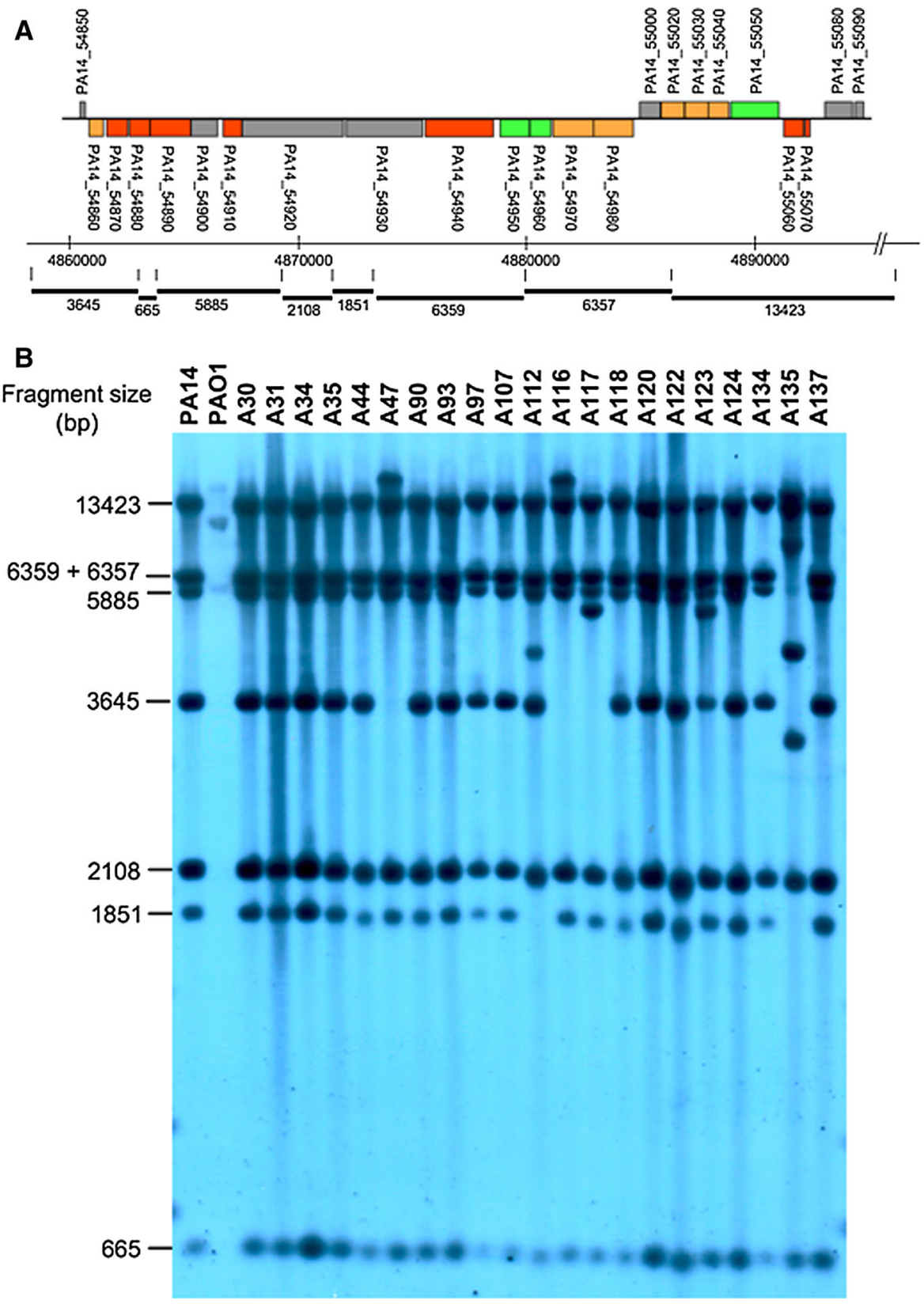

To demonstrate the activity of the predicted serine $O$-acetyltransferase PA14_54880, we tested whether PA14_54880 would complement a cysE mutation in the E. coli strain MG1655-C. As shown in Fig. 3d, cysteine-indepent growth occurred in the corresponding wildtype strain MG1655, but not in MG1655-C. Growth was restored in this mutant with $E$. coli cysE gene (carried by pET21-cysE) and with PA14_54880 (carried by plasmid pME10209) confirming the predicted function of this gene.

Finally we tested if the AraC-type regulator PA14_54870 would be able to replace PchR in $P$. aeruginosa or $P$. protegens. However, expression of this gene under $\mathrm{P}_{t a c}$ control did not allow the Pvdnegative pchR mutants PAO6402 and CHA1222 to produce Pch and EPch, respectively (data not shown). 
Clearly, PA14_54870 is not able to function as a transcriptional activator with Pch or EPch as effectors.

Structural identification of the metabolite specified by PA14GI-6

Based on bioinformatics and complementation experiments we predicted that the molecule specified by PA14GI-6 would be essentially composed of two cysteine-derived rings joined to salicylate. To purify large amounts of this molecule for structural identification, we generated the two Pvd and Pch-negative overexpression strains PA14-106 and PA14-109, in which genes of the first operon (PA14_54940 to PA14_54910) or those of both operons (PA14_54940 to PA14_54910 and PA14_54900 to PA14_54880) are expressed under $\mathrm{P}_{t a c}$ control. HPLC analysis (Fig. 4a) of culture supernatant extracts showed one major peak, irrespective of whether one (trace e) or both operons (trace f) had been overexpressed. This peak was different from those corresponding to Pch/EPch (traces a [Pch standard] and c [extract of the Pvdnegative strain PA14-98]) and was not produced with an extract of the Pvd- and Pch-negative strain PA1499 in which the two operons had not been artificially overexpressed (trace d). Surprisingly, the retention time of this peak was identical with that of Dha. For further structural identification of the PA14GI-6specified metabolite, the culture supernatant extract of PA14-109 was washed, purified on a metal-free silica gel column and subsequently analyzed by electrospray mass spetrometry. The ionic profile presented a peak at $m / z 224\left(\mathbf{M}+\mathrm{H}^{+}\right)$corresponding to the molecular weight of Dha $(\mathrm{MW}=223$ ). TLC analysis confirmed these results in that the PA14GI-6specified metabolite co-migrated perfectly with a synthetic Dha standard (Fig. 4b). Finally, we investigated the stereochemistry of the compound by chiral HPLC and found that it had the same retention time as $(R)$-Dha, the byproduct of EPch biosynthesis (Fig. 4c).

Identification of GI-6 in clinical and environmental $P$. aeruginosa isolates

To easily detect potential GI-6 carriers among natural isolates of $P$. aeruginosa, a PCR-based screening method was developed which is based on the size differences of pchE and PA14_54930. This method produces a 1,409 bp fragment caracteristic for $p c h E_{\mathrm{Pa}}$, and an additional fragment of $524 \mathrm{bp}$ characteristic for a gene resembling PA14_54930. We screened 110 clinical (isolated from patients) and 42 environmental $P$. aeruginosa isolates from different geographical origins and identified a total of 21 potential GI-6 carriers (data not shown). To test whether the entire genomic island was conserved in these candidates, chromosomal DNA was isolated, cleaved with BamHI and hybridized against a PA14GI-6- specific probe. As illustrated in Fig. 5, Southern analysis revealed that most isolates had a banding pattern which was identical to that of PA14. In some cases, the pattern was slightly modified, probably because not all BamHI sites are conserved. Although we cannot exclude that certain isolates of a given collection might be directly related, the identification of GI-6 in clinical as well as environmental isolates from different geographical origin suggests that GI-6 confers (or had conferred at some stage) a selective advantage to its carrier.

\section{Discussion}

Comparing the accessory genome of the $P$. aeruginosa strains C3719, LESB58, PAO1, PA7, PA14, PA2192, PACS2 revealed a total of 89 RGP's, in which different inserts of foreign DNA are found (Klockgether et al. 2011). These DNA inserts, which apparently have been acquired by horizontal gene transfer, contribute to the ongoing evolution of the $P$. aeruginosa genome by conferring specific phenotypes that are advantageous under certain selective conditions. In this work we have focused on PA14GI-6, one of the inserts found at RGP5 of strain PA14. As illustrated in Fig. 1, this insert harbors a gene cluster which ressembles those for the biosynthesis of the enantiomeric siderophores Pch and EPch. While EPch has so far been found in certain strains of $P$. protegens only (Youard et al. 2011), Pch seems more widely distributed and has been isolated from several pseudomonads ( $P$. aeruginosa, $P$. fluorescens, P. akbaalia), from members of the Burkholderia cepacia complex, and recently also from the plant pathogen Streptomyces scabies (Cox et al. 1981; Cuppels et al. 1987; Terano et al. 2002; Thomas 2007; Phoebe et al. 2001; Seipke et al. 2011). We thus hypothesized that an ancester of the genomic island PA14GI-6 may have 
been involved at some stage in the dissemination of Pch/EPch biosynthetic genes between these different bacterial species and genera and wondered what compound this island would specify todate. A detailed bioinformatics analysis of its Pch/EPch-related gene cluster (PA14_54940 to PA14_54870) predicted a compound consisting of salicylate linked to two cysteine-derived thiazoline rings which may have the same stereochemical configuration as those of EPch (Table 2). Having a large set of mutations in potential homologs of these genes at hand, we were able to test and confirm the predicted functions of PA14_54940 as a bifunctional salicylate synthase/ salicyl-AMP ligase (for generation and activation of salicylate; Fig. 2), of PA14_54930 as a Dha synthetase (for coupling salicylate with a cysteine-derived thiazoline ring; Fig. 2), of PA14_54910 as a type II thioesterase (for quality control; Reimmann et al. 2004), and of PA14_54880 as a serine $O$-acetyltransferase (for increased cysteine biosynthesis; Kredich 1996).

Expression of the entire gene cluster and structural analysis of the specified metabolite revealed its identity with ( $R$ )-Dha (Fig. 4), an iron chelator with antibacterial, antifungal and antitumor activity (Carmi et al. 1994; Elliot et al. 1988). Despite these interesting properties, the identification of Dha came as a surprise, as the gene cluster clearly codes for a PchF homolog (PA14_54920), and for two potential tailoring proteins (PA14_54900 and PA14_54890). Obviously, biosynthesis of a larger metabolite containing two thiazoline rings is terminated prematurely, and a biosynthetic intermediate is released from the thiotemplate PA14_54930 giving rise to Dha. Indeed, Dha was described as a byproduct of Pch biosynthesis in $P$. aeruginosa, namely when the PchE-bound intermediate hydroxyphenyl-thiazoline is released by slow hydrolysis of the thioester bond (Serino et al. 1997; Patel et al. 2003; Quadri et al. 1999).

Why then would biosynthesis not proceed to the end? Given that Dha contains only a single thiazoline ring it is likely that during evolution, one or several mutations in PA14_54920 have rendered this PchF homolog non-functional. Analysis of the characteristic sequence motifs in the predicted adenylation-thiolation-condensation/cylization domains, and comparison with the motifs of PchF from P. aeruginosa and $P$. protegens, revealed a very good motif conservation except for an alternative key residue in the
PA14_54920 thiolation domain (GGTSL instead of GGDSL). However, replacing the threonine codon against an aspartate codon did not alter metabolite production (data not shown), suggesting that additional mutations in PA14_54920 may prevent biosynthesis to proceed.

In conclusion, we have shown here that PA14GI-6 does not (or no longer) code for a Pch/EPch-related siderophore but has evolved to confer the ability of Dha production to its host. The maintenance of GI-6 in a large number of clinical and environmental $P$. aeruginosa isolates (Fig. 5) indicates either that Dha production could confer a selective advantage under certain conditions or that the presence of this rather small GI does not have a fitness cost.

Acknowledgments We wish to thank Zeb A. Youard for help with degenerate primer design, Paul Majcherczyk for HPLC analyses, and Nadja Leimer and Luis Alejandro González Blázquez for carrying out initial experiments on this project. This work as supported by the Swiss National Foundation for scientific research (project 31003A-132998).

\section{References}

Bachmann BJ (1987) Derivations and genotypes of some mutant derivatives of Escherichia coli K-12. In: Neidbordt FC, Ingraham JL, Low KB, Magasanik B, Schaechter M, Umbarger HE (eds) Escherichia coli and Salmonella typhimurium: cellular and molecular biology, vol 2. American Society for Microbiology, Washington, pp 1190-1219

Carmi R, Carmeli S, Levy E, Gough FJ (1994) (+)-(S)-dihydroaeruginoic acid, an inhibitor of Septoria tritici and other phytopathogenic fungi and bacteria, produced by Pseudomonas fluorescens. J Nat Prod 57:1200-1205

Cox CD, Rinehart KL, Moore ML, Cook JC (1981) Pyochelin: novel structure of an iron-chelating growth promoter for Pseudomonas aeruginosa. Proc Natl Acad Sci USA 78:4256-4260

Cuppels DA, Stipanovic RD, Stoessl A, Stothers JB (1987) The constitution and properties of a pyochelin-zinc complex. Can J Chem 65:2126-2130

D’Argenio DA, Gallagher LA, Berg CA, Manoil C (2001) Drosophila as a model host for Pseudomonas aeruginosa infection. J Bacteriol 183:1466-1471

Du L, Lou L (2010) PKS and NRPS release mechanisms. Nat Prod Rep 27:255-278

Elliot CA, Kelly KF, Bonna RL, Wardlaw TR, Burns ER (1988) In vitro antiproliferative activity of $2^{\prime}$-(2-hydroxyphenyl)$2^{\prime}$ thiazoline- $4^{\prime}$ carboxylic acid and its methyl ester on L1210 and P388 murine neoplasms. Cancer Chemother Pharm 21:233-236

Farinha MA, Kropinski AM (1990) High efficiency electroporation of Pseudomonas aeruginosa using frozen cell suspensions. FEMS Microbiol Lett 58:221-225 
Gallagher LA, Manoil C (2001) Pseudomonas aeruginosa kills Caenorhabditis elegans by cyanide poisoning. J Bacteriol 183:6207-6214

Gamper M, Ganter B, Polito MR, Haas D (1992) RNA processing modulates the expression of the $\operatorname{arcDABC}$ operon in Pseudomonas aeruginosa. J Mol Biol 226:943-957

Heeb S, Blumer C, Haas D (2002) Regulatory RNA as mediator in GacA/RsmA-dependent global control of exoproduct formation in Pseudomonas fluorescens CHA0. J Bacteriol 184:1046-1056

Hoegy F, Lee X, Noel S, Rognan D, Mislin GL, Reimmann C, Schalk IJ (2009) Stereospecificity of the siderophore pyochelin outer membrane transporters in fluorescent pseudomonads. J Biol Chem 284:14949-14957

Juhas M, van der Meer JR, Gaillard M, Harding RM, Hood DW, Crook DW (2008) Genomic islands: tools of bacterial horizontal gene transfer and evolution. FEMS Microbiol Rev 33:376-393

Klockgether J, Cramer N, Wiehlmann L, Davenport CF, Tümmler B (2011) Pseudomonas aeruginosa genomic structure and diversity. Front Microbiol 2:150

Kredich NM (1996) Biosynthesis of cysteine. In: Neidhardt FC, Curtiss III R, Ingraham JL, Lin ECC, Low KB, Magasanik B, Raznikoff WS, Riley M, Schaechter M, Umbarger HE (eds) Escherichia coli and Salmonella: cellular and molecular biology. ASM Press, Washington, pp 515-527

Laville J, Blumer C, Von Schroetter C, Gaia V, Défago G, Keel C, Haas D (1998) Characterization of the hcnABC gene cluster encoding hydrogen cyanide synthase and anaerobic regulation by ANR in the strictly aerobic biocontrol agent Pseudomonas fluorescens CHA0. J Bacteriol 180:3187-3196

Lee DG, Urbach JM, Wu G, Liberati NT, Feinbaum RL, Miyata S, Diggins LT, He J, Saucier M, Déziel E, Friedman L, Li L, Grills G, Montgomery K, Kucherlapati R, Rahme LG, Ausubel FM (2006) Genomic analysis reveals that Pseudomonas aeruginosa virulence is combinatorial. Genome Biol 7:R90

Lin P-C, Youard ZA, Reimmann C (2013) In vitro-binding of the natural siderophore enantiomers pyochelin and enantiopyochelin to their AraC-type regulators PchR in Pseudomonas. Biometals 26:1067-1073

Lyczak JB, Cannon CL, Pier GB (2002) Lung infections associated with cystic fibrosis. Clin Microbiol Rev 15:194-222

Mathee K, Narasimhan G, Valdes C, Qiu X, Matewish JM, Koehrsen M, Rokas A, Yandava CN, Engels R, Zeng E, Olavarietta R, Doud M, Smith RS, Montgomery P, White JR, Godfrey PA, Kodira C, Birren B, Galagan JE, Lory S (2008) Dynamics of Pseudomonas aeruginosa genome evolution. Proc Natl Acad Sci USA 105:3100-3105

Maurhofer M, Reimmann C, Schmidli-Sacherer P, Heeb S, Haas D, Défago G (1998) Salicylic acid biosynthetic genes expressed in Pseudomonas fluorescens strain P3 improve the induction of systemic resistance in tobacco against tobacco necrosis virus. Phytopathology 88:678-684

Michel L, Bachelard A, Reimmann C (2007) Ferripyochelin uptake genes are involved in pyochelin-mediated signalling in Pseudomonas aeruginosa. Microbiology 153:15081518

Patel HM, Tao J, Walsh CT (2003) Epimerization of an L-cysteinyl to a D-cysteinyl residue during thiazoline ring formation in siderophore chain elongation by pyochelin synthetase from Pseudomonas aeruginosa. Biochemistry 42:10514-10527

Phoebe CH Jr, Combie J, Albert FG, Van Tran K, Cabrera J, Correira HJ, Guo Y, Lindermuth J, Rauert N, Galbraith W, Selitrennikoff CP (2001) Extremophilic orgainisms as and unexplored source of antifungal compounds. J Antibiot 54:56-65

Plotnikova JM, Rahme LG, Ausubel FM (2000) Pathogenesis of the human opportunistic pathogen Pseudomonas aeruginosa PA14 in Arabidopsis. Plant Physiol 124:1766-1774

Pukatzki S, Kressin RH, Mekalanos JJ (2002) The human pathogen Pseudomonas aeruginosa utilizes conserved virulence pathways to infect the social amoeba Dictyostelium discoideum. Proc Natl Acad Sci USA 99:3159-3164

Quadri LEN, Keating TA, Patel HM, Walsh CT (1999) Assembly of the Pseudomonas aeruginosa nonribosomal peptide siderophore pyochelin: in vitro reconstitution of aryl-4,2-bisthiazoline synthetase activity from PchD, PchE and PchF. Biochemistry 38:14941-14954

Reimmann C (2012) Inner-membrane transporters for the siderophores pyochelin in Pseudomonas aeruginosa and enantio-pyochelin in Pseudomonas fluorescens display different enantioselectivities. Microbiology 158:13171324

Reimmann C, Serino L, Beyeler M, Haas D (1998) Dihydroaeruginoic acid synthetase and pyochelin synthetase, products of the $p c h E F$ genes, are induced by extracellular pyochelin in Pseudomonas aeruginosa. Microbiology 144:3135-3148

Reimmann C, Patel HM, Serino L, Barone M, Walsh CT, Haas D (2001) Essential PchG-dependent reduction in pyochelin biosynthesis of Pseudomonas aeruginosa. J Bacteriol 183:813-820

Reimmann C, Patel HM, Walsh CT, Haas D (2004) PchC thioesterase optimizes nonribosomal biosynthesis of the peptide siderophore pyochelin in Pseudomonas aeruginosa. J Bacteriol 186:6367-6373

Sambrook J, Russell DW (2001) Molecular cloning. A laboratory manual. Cold Spring Laboratory Press, NY

Schmidt KD, Tümmler B, Römling U (1996) Comparative genome mapping of Pseudomonas aeruginosa PAO with $P$. aeruginosa $\mathrm{C}$, which belongs to a major clone in cystic fibrosis patients and aquatic habitats. J Bacteriol 178:85-93

Schnider U, Keel C, Blumer C, Troxler J, Défago G, Haas D (1995) Amplification of the housekeeping sigma factor in Pseudomonas fluorescens $\mathrm{CHA} 0$ enhances antibiotic production and improves biocontrol abilities. J Bacteriol 177:5387-5392

Schwyn B, Neilands JB (1987) Universal chemical assay for the detection and determination of siderophores. Anal Biochem 160:47-56

Seipke RF, Song L, Bicz J, Laskaris P, Yaxley AM, Challis GL, Loria R (2011) The plant pathogen Streptomyces scabies 87-22 has a functional pyochelin biosynthetic pathway that is regulated by TetR- and AfsR-family proteins. Microbiology 157:2681-2693

Serino L, Reimmann C, Visca P, Beyeler M, Della Chiesa V, Haas D (1997) Biosynthesis of pyochelin and dihydroaeruginoic acid requires the iron-regulated $p \operatorname{ch} D C B A$ operon in Pseudomonas aeruginosa. J Bacteriol 179:248-257 
Song L, Zhang XH (2009) Innovation for ascertaining genomic islands in PAO1 and PA14 of Pseudomonas aeruginosa. Chin Sci Bull 54:3991-3999

Song L, Zhang XH (2011) Acurate localization and excision of genomic islands in four strains of Pseudomonas aeruginosa and Pseudomonas fluorescens. Chin Sci Bull 56:987-995

Stanisich VA, Holloway BW (1972) A mutant sex factor of Pseudomonas aeruginosa. Genet Res 19:91-108

Sturgill G, Toutain CM, Komperda J, O'Toole GA, Rather PN (2004) Role of CysE in production of an extracellular signaling molecule in Providencia stuartii and Escherichia coli: loss of cysE enhances biofilm formation in Escherichia coli. J Bacteriol 186:7610-7617

Terano H, Nomoto K, Takase S (2002) Siderophore production and induction of iron-regulated proteins by a microorganism from rhizosphere of barley. Biosci Biotechnol Biochem 66:2471-2473

Thomas MS (2007) Iron acquisition mechanisms of the Burkholderia cepacia complex. Biometals 20:431-452

Van Delden C, Iglewski B (1998) Cell-to-cell signaling and Pseudomonas aeruginosa infections. Emerg Infect Dis 4:551-560

Visca P, Serino L, Orsi N (1992) Isolation and characterization of Pseudomonas aeruginosa mutants blocked in the synthesis of pyoverdin. J Bacteriol 174:5727-5731

Voisard C, Rella M, Haas D (1988) Conjugative transfer of plasmid RP1 to soil isolates of Pseudomonas fluorescens is facilitated by certain large RP1 deletions. FEMS Microbiol Lett 55:9-14
Voisard C, Bull C, Keel C, Laville J, Maurhofer M, Schnider U, Défago G, Haas D (1994) Biocontrol of root diseases by Pseudomonas fluorescens CHA0: current concepts and experimental approaches. In: O'Gara F, Dowling FDL, Boesten B (eds) Molecular ecology of rhizosphere microorganisms, pp 67-69

Watson AA, Alm RA, Mattick JS (1996) Construction of improved vectors for protein production in Pseudomonas aeruginosa. Gene 172:163-164

Ye RW, Haas D, Ka JO, Krishnapillai V, Zimmermann A, Baird C, Tiedje JM (1995) Anaerobic activation of the entire denitrification pathway in Pseudomonas aeruginosa requires Anr, an analog of Fnr. J Bacteriol 177:3606-3609

Youard ZA, Reimmann C (2010) Stereospecific recognition of pyochelin and enantio-pyochelin by the PchR proteins in fluorescent pseudomonads. Microbiology 156:1772-1782

Youard ZA, Mislin GL, Majcherczyk PA, Schalk IJ, Reimmann C (2007) Pseudomonas fluorescens CHA0 produces enantio-pyochelin, the optical antipode of the Pseudomonas aeruginosa siderophore pyochelin. J Biol Chem 282:35546-35553

Youard ZA, Wenner N, Reimmann C (2011) Iron acquisition with the natural siderophore enantiomers pyochelin and enantio-pyochelin in Pseudomonas species. Biometals 24:513-522 